\title{
Visual field loss with capillary non-perfusion in preproliferative and early proliferative diabetic retinopathy
}

Caroline K L Chee, Declan W Flanagan

\begin{abstract}
Thirty two eyes of 19 patients with capillary non-perfusion from preproliferative and early proliferative diabetic retinopathy underwent visual field testing on the $30-2$ program of the Humphrey visual field analyser. The mean defect (MD) p value was $<5 \%$ in $30(94 \%)$ eyes and the corrected pattern standard deviation (CPSD) was $<10 \%$ in 31 . (97\%) eyes. Areas of capillary non-perfusion demonstrated by fundal fluorescein angiography were closely associated with areas of reduced retinal sensitivity in these $\mathbf{3 1}$ eyes. More severe visual field defects were present in non-insulin dependent diabetics and in older patients. MD and CPSD $p$ values of less than $0.5 \%$ and $1 \%$ respectively were found to be associated with non-insulin dependent diabetes $(p<0.05$ and $p<0.01$ respectively) and with the older age group $(\mathbf{p}<0.05)$. There was no correlation between severity of field defects with hypertension and degree of retinopathy.

(Brf Ophthalmol 1993; 77: 726-730)
\end{abstract}

Visual field defects are commonly associated with diabetic retinopathy. They have been documented by Roth ${ }^{1}$ and Caird and associates ${ }^{2}$ in 1969, and since then by Taylor and Dobree, ${ }^{3}$ Wiznia and associates, ${ }^{4}$ Griete et $a l,{ }^{5}$ Bek,,${ }^{6}$ Bek and Lund-Anderson, ${ }^{78}$ and Trick et al. ${ }^{9}$

It was our clinical observation that patients who demonstrated areas of capillary nonperfusion on fundal fluorescein angiography had visual field defects which correlated with the corresponding areas of capillary non-perfusion. This study was performed firstly to detect the presence of visual field defects in patients with preproliferative and early proliferative diabetic retinopathy who had significant retinal ischaemia, correlating the severity of field defects to age, type of diabetes, stage of retinopathy, and blood pressure; and secondly to assess whether capillary non-perfusion in these eyes is consistently associated with visual field defects as determined by the Humphrey field analyser.

Department of

Ophthalmology,

Addenbrooke's Hospital,

Cambridge

C K L Chee

D W Flanagan

Correspondence to: Caroline Chee, Department of Ophthalmology,

National University Hospital

Lower Kent Ridge Road,

Singapore 0511.

Accepted for publication

18 May 1993

\section{Methods}

From May to July 1992, 39 eyes of 23 patients with preproliferative and early proliferative diabetic retinopathy were selected from the diabetic retinopathy clinic on the basis of biomicroscopic findings. All patients had moderate to marked retinal ischaemia, demonstrated by multiple blot haemorrhages, venous dilatation or beading, cotton wool spots, or intraretinal micro- vascular abnormalities. Patients with proliferative retinopathy had either disc or peripheral neovascularisation but no previous peripheral laser photocoagulation. Previous macular photocoagulation was not an exclusion criterion. None of the patients had media opacities.

Fundal fluorescein angiography was performed using the Kowa Pro I fundus camera with Ilford FP 4 Plus ASA 125 film, after injection of $2 \mathrm{ml}$ of $20 \%$ sodium fluorescein. Threshold visual field analysis with the 30-2 program of the Humphrey automated field analyser was performed. Seven eyes of four patients were excluded from the study for the following reasons: three eyes showed either no capillary non-perfusion or areas of non-perfusion more than 3 disc diameters away from the fovea; one patient was unable to perform the automated perimetry reliably; another was found to have an asymptomatic left upper quadrantanopia. Thirty two eyes of 19 patients remained in the study.

The 19 patients were between 30 and 82 years of age (mean 56.84 (SD 14.18) years). There were 13 men and six women. Thirteen patients were non-insulin dependent diabetics, six were insulin dependent; six were hypertensive, 13 were normotensive. Of the 32 eyes, 18 eyes of 12 patients had proliferative retinopathy, and 14 eyes of 10 patients had preproliferative retinopathy.

The number of patients with visual field defects was obtained by observing areas of absolute and relative loss of sensitivity on the greytone format of the printout. The Humphrey Statpac 2 program provides global indices which compare the threshold visual field results with those of age-controlled normals. The mean defect (MD) is the mean elevation or depression of the overall field compared with the age-matched normal reference field. The corrected pattern standard deviation (CPSD) is the measurement of the degree to which the shape of the patient's hill of vision deviated from the normal age corrected reference field after correction for the patient's intratest variability in response. The number of patients who had abnormal fields based on the $p$ values of the MD and CPSD were recorded. The severity of field defects based on the MD and CPSD $p$ values was correlated with the age, type of diabetes, presence of hypertension, and type of retinopathy. The $\chi^{2}$ test was used to analyse the correlation of severity of fields with type of diabetes, hypertension, and retinopathy and Student's $t$ test was used to analyse the correlation of severity of fields with age, the type of diabetes with age, and the type of diabetes with duration of diabetes.

The visual fields of the 30 eyes were compared 
Table 1 Results of Humphrey Statpac 2 global indices

\begin{tabular}{ccl}
\hline$p$ Values (\%) & No of patients (\%) & Cumulative no $(\%)$ \\
\hline$M^{\star}:$ & & \\
$<0 \cdot 5$ & $19(59)$ & $19(59)$ \\
$<1$ & $1(3)$ & $21(62)$ \\
$<2$ & $5(6)$ & $25(78)$ \\
$<5$ & $5(16)$ & $30(94)$ \\
$<10$ & 0 & - \\
$>10$ & $2(6)$ & $32(100)$ \\
CPSD not: & $11(34)$ & $11(34)$ \\
$<0 \cdot 5$ & $7(21)$ & $18(55)$ \\
$<1$ & $6(19)$ & $24(75)$ \\
$<2$ & $4(13)$ & $28(88)$ \\
$<5$ & $3(9)$ & $31(97)$ \\
$<10$ & $1(3)$ & $32(100)$ \\
$>10$ & & \\
\hline
\end{tabular}

${ }^{\star} M D=$ mean defect. Mean elevation or depression of the overal field compared to the age matched normal reference field. field compared to the age matched normal reference field. $+C P S D=$ corrected pattern standard deviation. Measurement of
the degree to which the shape of the patient's hill of vision deviated from the normal age corrected reference field, after correction for the patient's intratest variability in response.

with their fluorescein fundus angiograms to assess the correlation between visual field loss and areas of capillary non-perfusion. The fluorescein angiograms were inverted about a horizontal axis and superimposed onto the numeric format of the Humphrey field test result so that the fovea corresponded with the fixation point and the optic disc corresponded with the blind spot.

\section{Results}

Thirty of the 32 eyes (94\%) had obvious areas of reduced sensitivity on the greytone printout. The MD of these 30 eyes had $p$ values of less than $5 \%$ (see Table 1). This means that only $5 \%$ of the normal age-matched population has an MD equal to or poorer than these patients. Nineteen eyes $(59 \%)$ showed MD $p$ values of less than $0.5 \%$. The CPSD had $p$ values of less than $10 \%$ in 31 eyes (97\%), including all those with MD $\mathrm{p}<10 \%$.

Visual field defects were found to be more severe in the older patients. The average age of the patients with CPSD p values of less than $1 \%$ was $61 \cdot 28(14 \cdot 15)$ years, which was significantly more than the average age of patients with CPSD p values of between 2 and $10 \%$ who had an average age of $51.14(12.46)$ years $(p<0.05)$. Likewise, patients with MD p values of $0.5 \%$ had an average age of 60.95 (13.09) years, significantly older than those with $M D p$ values of greater than $0.5 \%$ who had an average age of $50.85(14.03)$ years $(\mathrm{p}<0.05)$ (Table 2A).

Patients with non-insulin dependent diabetes mellitus (NIDDM) were found to have significantly poorer visual fields compared to those with insulin dependent diabetes mellitus (IDDM). The differences between the proportions of NIDDM and IDDM patients having MD $p$ values of less than $0.5 \%$ and CPSD $p$ values

Table $2 A$ Severity of field defects (MD and CPSD) and age

\begin{tabular}{|c|c|c|c|c|}
\hline & $\begin{array}{l}\text { No of } \\
\text { eyes }\end{array}$ & $\begin{array}{l}\text { Mean age }(S D) \\
\text { years }\end{array}$ & t Statistic & p Value \\
\hline $\begin{array}{l}\text { MD: } \\
\quad<0.5 \% \\
>0.5 \% \\
\text { CPSD. }\end{array}$ & $\begin{array}{l}19 \\
13\end{array}$ & $\begin{array}{l}60.96(13.09) \\
50.85(14.03)\end{array}$ & 2.0828 & 0.046 \\
\hline $\begin{array}{l}<1 \% \\
>1 \%\end{array}$ & $\begin{array}{l}18 \\
14\end{array}$ & $\begin{array}{l}61 \cdot 28(14 \cdot 15) \\
51 \cdot 14(12 \cdot 46)\end{array}$ & $2 \cdot 1149$ & 0.043 \\
\hline
\end{tabular}

Table $2 B$ Severity of field defects (MD and CPSD) and age in NIDDM

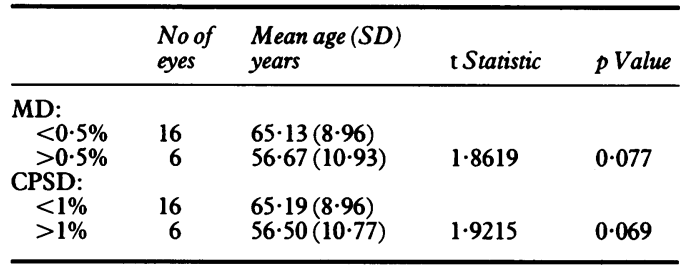

Table $2 C$ Severity of field defects (MD and CPSD) and age in IDDM

\begin{tabular}{|c|c|c|c|c|}
\hline & $\begin{array}{l}\text { No of } \\
\text { eyes }\end{array}$ & $\begin{array}{l}\text { Mean age }(S D) \\
\text { years }\end{array}$ & t Statistic & p Value \\
\hline \multicolumn{5}{|l|}{ MD: } \\
\hline$<0.5 \%$ & 3 & $38 \cdot 67(7 \cdot 51)$ & & \\
\hline$>0.5 \%$ & 7 & $45 \cdot 86(15 \cdot 20)$ & -0.7619 & 0.3477 \\
\hline \multicolumn{5}{|l|}{ CPSD: } \\
\hline$<1 \%$ & 2 & $30 \cdot 00(0)$ & & \\
\hline$>1 \%$ & 8 & $47 \cdot 13(12 \cdot 76)$ & -1.8155 & $0 \cdot 107$ \\
\hline
\end{tabular}

of less than $1 \%$ were statistically significant $(\mathrm{p}<0.05$ and $\mathrm{p}<0.01$ respectively, see Table 3 ). Since our NIDDM patients were, as would be expected, significantly older than the IDDM patients $(p=0.03$, Table $4 A)$, we separated the two groups to assess if severity of field loss could be correlated to age independent of insulin dependence. We found that in the NIDDM group, the correlation between severity of field loss and age remained (Table 2B), although, unsurprisingly, at a lower level of significance $(p<0 \cdot 1)$. The numbers of patients who were insulin dependent were too small for accurate statistical analysis; however, this group showed no difference in age between the patients with more severe field defects compared with those with less severe field defects, and in fact those with poorer fields were of a younger age (Table 2C).

There was no significant difference in the MD and CPSD $p$ values between the hypertensives and normotensives, and those with proliferative and non-proliferative diabetic retinopathy (Table 3).

When visual field test results in these eyes were superimposed onto the inverted fluorescent fundus angiogram, the areas of capillary nonperfusion correlated closely to areas of reduced retinal sensitivity. The severity of the field loss was variable. In some patients, there were absolute losses corresponding to areas of complete capillary closure (Fig 1). In other patients with less severe capillary closure, there was only a relative loss of retinal sensitivity (Fig 2). Central field defects were present in patients with maculopathy not related to capillary nonperfusion.

In one patient, the visual fields of both eyes appeared normal on the greytone display (Fig $3 A)$. The MD and CPSD values in these two eyes were also unremarkable. Despite the fact that the visual fields were normal, areas of capillary nonperfusion corresponded to areas of relatively reduced retinal sensitivity in the right eye (Fig 3B). However, there was poor correlation between capillary non-perfusion and reduced retinal sensitivity in the other eye. This patient was a hypertensive 43-year-old woman with bilateral proliferative retinopathy, and had been diagnosed as having NIDDM 3 months earlier. 
Table 3 Severity of field defects and type of diabetes mellitus, presence of hypertension, a nd type of retinopathy

\begin{tabular}{|c|c|c|c|c|c|c|c|}
\hline Field defect & $I D D M$ & v NIDDM & High $B P$ v & Normal BP & $P D R$ & $\mathbf{v}$ & $N P D R$ \\
\hline $\begin{array}{l}\text { MD: } \\
<0.5 \% \\
>0.5 \% \\
\chi^{2} \\
\text { Significance } \\
\text { CPSD. }\end{array}$ & $\begin{array}{lr}3 & \\
7 & 5 . \\
& p<0\end{array}$ & $\begin{array}{r}16 \\
6 \\
64\end{array}$ & $\begin{array}{ll}7 & \\
4 & \\
& 0.1262 \\
& p>0.1\end{array}$ & $\begin{array}{r}12 \\
9\end{array}$ & $\begin{array}{ll}9 & \\
9 & \\
& 1 \\
p & >0\end{array}$ & & $\begin{array}{r}10 \\
4\end{array}$ \\
\hline $\begin{array}{l}<1 \% \\
>1 \% \\
\chi^{2} \\
\text { Significance }\end{array}$ & $\begin{array}{l}2 \\
8 \\
\\
\\
p<0 .\end{array}$ & $40^{16} 6$ & $\begin{array}{ll}7 & \\
3 & 1 \cdot 117 \\
& p>0.1\end{array}$ & $\begin{array}{l}11 \\
11\end{array}$ & $\begin{array}{r}10 \\
8 \\
p>0\end{array}$ & 081 & $\begin{array}{l}8 \\
6\end{array}$ \\
\hline
\end{tabular}

IDDM = insulin dependent diabetes mellitus; NIDDM =non-insulin dependent diabetes mellitus $\mathrm{BP}=$ blood pressure; $\mathrm{PDR}=$ proliferative diabetic retinopathy;

$\mathrm{NPDR}=$ non-proliferative diabetic retinopathy.

\begin{tabular}{|c|c|c|c|c|}
\hline$D M$ & $\begin{array}{l}\text { No of } \\
\text { patients }\end{array}$ & $\begin{array}{l}\text { Mean age }(S D) \\
\text { years }\end{array}$ & t Statistic & p Value \\
\hline $\begin{array}{l}\text { IDDM: } \\
\text { NIDDM }\end{array}$ & $\begin{array}{r}6 \\
13\end{array}$ & $\begin{array}{l}43 \cdot 83(14 \cdot 25) \\
62 \cdot 85(9 \cdot 66)\end{array}$ & 3.4379 & 0.003 \\
\hline
\end{tabular}

Table 4B Type of diabetes mellitus $\mathrm{v}$ duration of disease

\begin{tabular}{|c|c|c|c|c|}
\hline$D M$ & $\begin{array}{l}\text { No of } \\
\text { patients }\end{array}$ & $\begin{array}{l}\text { Mean duration } \\
(S D) \text { years }\end{array}$ & t Statistic & p Value \\
\hline $\begin{array}{l}\text { IDDM: } \\
\text { NIDDM }\end{array}$ & $\begin{array}{r}6 \\
13\end{array}$ & $\begin{array}{l}31.83(13.85) \\
14.15(10.69)\end{array}$ & 3.059 & 0.007 \\
\hline
\end{tabular}

\section{Discussion}

We found that severity of field loss is associated with two factors: NIDDM and age. Trick et al have recorded that visual field defects occur more frequently in non-insulin dependent

Figure 1 Humphrey 30-2 result superimposed onto an inverted fundal fluorescein angiogram showing absolute loss of sensitivity associated with areas of complete capillary closure.
Figure 2 Humphrey 30-2 result superimposed onto an inverted fundal fluorescein angiogram showing relative loss of sensitivity associated with areas of partial capillary closure.
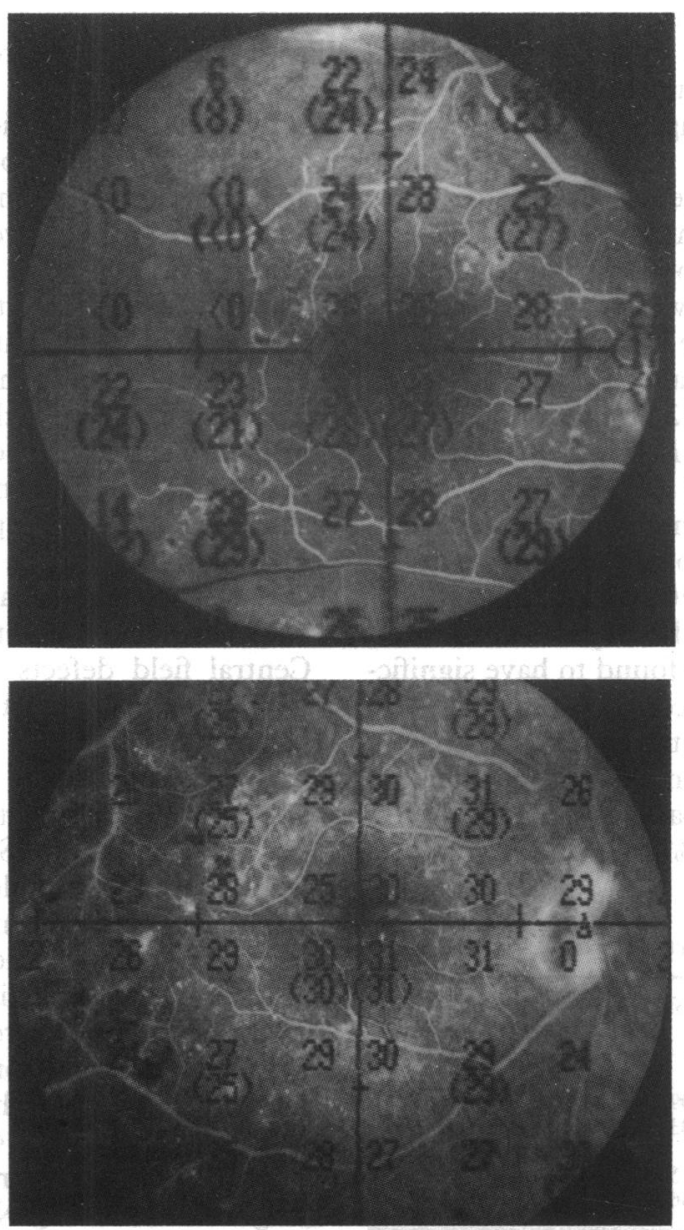

patients, 9 even in the absence of significant diabetic retinopathy. Roth' found that field defects were more commonly found in older patients with diabetes of short duration which is also consistent with our results, since our NIDDM patients had a significantly shorter duration of diabetes compared with the IDDM patients (Table 4B).

In 1984, Bell and Feldon ${ }^{10}$ demonstrated a linear correlation between visual function as determined by the Octopus automated static perimeter and capillary perfusion in 14 eyes with diabetic retinopathy. They also found foci of decreased visual sensitivity which corresponded to regions of good capillary perfusion in the central fields of diabetics, and attributed this to metabolic factors. Our findings are consistent with theirs in that we have found, using the Humphrey field analyser, that capillary nonperfusion in diabetic retinopathy is closely, although not constantly, associated with reduced retinal sensitivity. Areas of reduced sensitivity associated with maculopathy without capillary non-perfusion were also noted.

One patient in our study maintained good retinal sensitivity despite reduced capillary perfusion. This patient was relatively young at 43 years old. Younger patients had significantly less severe visual field loss. The reasons are not clear. Perhaps younger neurons are more resistant to hypoxia and metabolic imbalance or else the presence of a healthy choroid, not yet affected by atherosclerotic vascular disease, contributes to the maintenance of good retinal sensitivity. Reduced capillary perfusion may have to be established for a period of time before retinal function is affected. Engerman and Kern found that dogs in which diabetes had been induced, which were metabolically well controlled early in the disease, did not develop retinopathy, whereas those which were poorly controlled at the onset of disease developed retinopathy even if good control was instituted after the initial two and a half years of poor control. ${ }^{11}$ Insulin dependent diabetics may be resistant to developing retinopathy until a later stage if they are well controlled at the onset of the disease, thus they do not demonstrate significant field defects early in the disease. However, if they develop significant ischaemia while they are relatively young, proliferative disease develops more rapidly than in older patients because they have a greater capacity to produce angiogenesis factors.

This patient was a non-insulin dependent diabetic with proliferative diabetic retinopathy. She may have had poorly controlled diabetes mellitus for some time before diagnosis (since non-insulin dependent diabetes is more likely to be asymptomatic compared with insulin dependent diabetes), resulting in the development of significant capillary non-perfusion which, however, had not been given sufficient time to produce losses in retinal sensitivity; but because she is young and is capable of mounting a greater angiogenic response, she has developed proliferative diabetic retinopathy before any significant visual field loss has occurred. If visual field loss could be demonstrated when perimetry was repeated at a later date, there would be some support for the theory that reduced capillary 


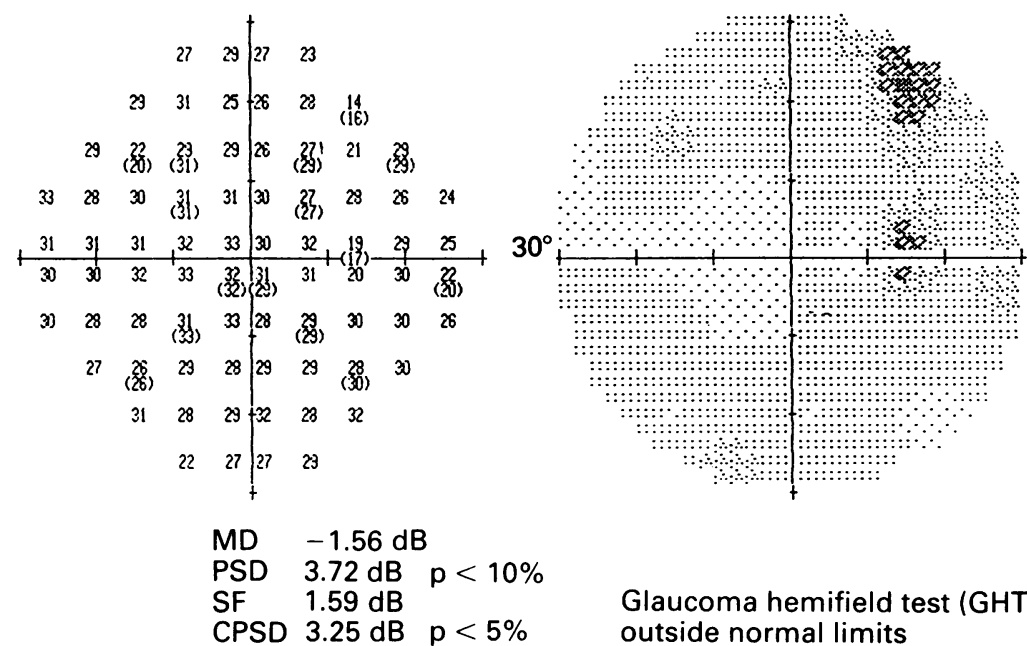

$$
\begin{aligned}
& 2 7 \quad 2 9 \longdiv { 2 0 } \quad 2 7 \\
& \text { 3) } \quad 22 \quad 23 \quad 27 \quad \text { (3) }
\end{aligned}
$$

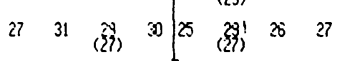

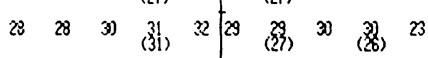

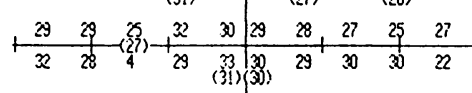

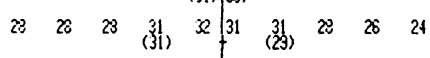

$$
\begin{aligned}
& 30 \quad \text { (3) } 31 \quad 27 \quad 30 \quad 29 \quad 39,29 \\
& \begin{array}{lllllll}
32 & 3) & 23 & 23 & 25 & 27
\end{array} \\
& 29 \quad 23 \quad 27 \quad 26 \\
& \text { MD }-0.03 \mathrm{~dB} \\
& \text { PSD } 2.38 \mathrm{~dB} \\
& \text { SF } \quad 1.98 \mathrm{~dB} \\
& \text { CPSD } 1.06 \mathrm{~dB}
\end{aligned}
$$

Figure $3 A$ Normal visual fields of a 43-year-old woman with proliferative woman with proliferatic retinopathy.
diabet

Figure 3B Humphrey 30-2 result superimposed onto an inverted fundal fluorescein angiogram of the patient in Figure $3 A$, showing relatively reduced sensitivity in areas of capillary non-perfusion.

perfusion must be present for some time before field loss occurs. Unfortunately, panretinal photocoagulation (PRP) which was performed on this patient invalidates attribution of any subsequent field loss solely to the capillary nonperfusion. A prospective study involving a larger sample size would be required to find out if reduction in retinal sensitivity occurs before or after closure of the retinal capillary beds, and to determine the interval between the two events

The mechanism by which PRP reduces blindness from proliferative diabetic retinopathy is

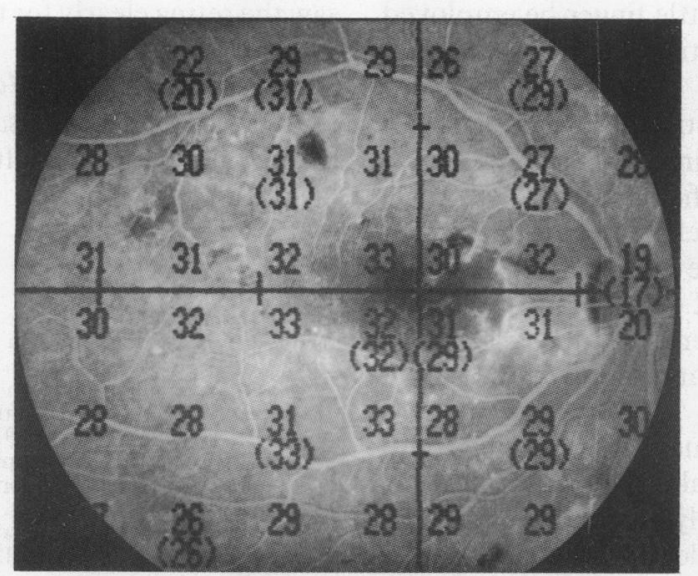

believed to be by destruction of ischaemic retina which provides the stimulus for neovascular proliferation. PRP is occasionally associated with peripheral visual field constriction. ${ }^{12}$ Our paper demonstrates that in the majority of patients, there is pre-existing visual field loss corresponding to areas of capillary nonperfusion on fluorescein fundus angiography. Laser photocoagulation applied to these areas is not likely to worsen the visual field. Areas of capillary non-perfusion, which are areas of ischaemic retina, would also be the logical target for photocoagulation. It should therefore be unnecessary to withhold laser treatment in patients with preproliferative retinopathy for fear of worsening the peripheral fields providing photocoagulation is applied to the areas of capillary non-perfusion.

We found that one patient with proliferative retinopathy maintained a good visual field despite having significant retinal capillary nonperfusion. She would therefore run the risk of losing peripheral visual field after panretinal photocoagulation, possibly to the extent of losing her driving licence. The visual field requirement for keeping one's driving licence in the United Kingdom is 120 degrees in the horizontal meridian, and 20 degrees above and 20 degrees below the horizontal with the Goldmann III4e isoptre. Loss of adequate driving fields resulting from panretinal photocoagulation would have considerable impact on patients whose lifestyles or livelihoods depend on driving. Automated perimetry may be useful before laser treatment, particularly in younger patients in order to identify patients at risk of losing visual fields. In these patients, laser treatment performed in the peripheral PRP pattern described by Blankenship, ${ }^{13}$ where laser photocoagulation is applied no further posteriorly than the midperiphery, is more likely to preserve peripheral field than central PRP which only spares a 2 disc diameter area centred on the fovea and papillomacular bundle. However, in eyes where capillary nonperfusion is present posterior to the equator, peripheral PRP is less likely to be effective.

In summary, we have found that over $90 \%$ of patients with capillary non-perfusion from diabetic retinopathy suffer from significant visual field loss. The severity of field loss is greater in non-insulin dependent diabetics and in older patients. Areas of capillary non-perfusion in preproliferative and proliferative diabetic retinopathy demonstrated by fundal flourescein angiography is closely associated with reduced retinal sensitivity detected by the Humphrey field analyser 30-2 threshold test.

We are grateful to Mrs Katherine Haslam for the photography and technical assistance.

Roth JA. Central visual field in diabetes. $\mathrm{Br} \mathcal{F}$ Ophthalmol 1969; 53: 16-25.

Caird FI, Pirie A, Ramsell IG. Diabetes and the eye. Oxford: Blackwell, 1969.

Taylor E, Dobree JH. Proliferative diabetic retinopathy: site and size of initial lesions. $\mathrm{Br}$ F Ophthalmol 1970; 54: 11-8.

Wiznia KI, Lieberman TW Leopold IH Visual fields in diabetic retinopathy. Br f Ophthalmol 1971; 55: 183-8.

5 Greite JH, Zumbansen HP, Adamczyk R. Visual field in diabetic retinopathy (DR). In: Greve EL, Verriest G, eds. Fourth International Visual Field Symposium, Bristol, 13-16 April 1980. The Hague: W Junk, 1981: 25-32 (Doc Ophthalmol Proc Series 26) 
6 Bek T. Coexistence of localized scotomata and neovascularizations in proliferative diabetic retinopathy. Acta Ophthalmol 1990; 68: 421-7.

7 Bek T, Lund-Anderson H. Localised blood-retinal barrier leakage and retinal light sensitivity in diabetic retinopathy.

8 Bek T, Lund-Anderson H. Cotton-wool spots and retinal light sensitivity in diabetic retinopathy. Br f Ophthalmol 1991, 75: 13-7.

9 Trick GL, Trick LR, Kilo C. Visual field defects in patients with insulin-dependent and noninsulin dependent diabetes. Ophthalmology 1990; 97: 475-82.

10 Bell JA, Feldon SE. Retinal microangiopathy: correlation of
OCTOPUS perimetry with fluorescein angiography. Arch Ophthalmol 1984; 102: 1294-8.

11 Engerman RL, Dern TS. Progression of incipient diabetic retinopathy during good glycaemic control. Diabetes 1987; 36: 808-12.

12 Hamilton AM, Townsend C, Khoury D, Gould E, Blach RK Xenon arc and argon laser photocoagulation in the treatmen of diabetic disc neovascularization part 1: effect on disc vessels, visual fields and visual acuity. Trans Ophthalmol Soc UK 1981; 101: 87-92.

13 Blankenship GW. A clinical comparison of central and peripheral argon laser panretinal photocoagulation for proliferative diabetic retinopathy. Ophthalmology 1981; 95: 170-7.

History of ophthalmology

\section{After Helmholtz}

Helmholtz's revelation of the ophthalmoscope in 1851 provoked a flood of debate in the literature.

James Dixon, of the London Ophthalmological Hospital feared that intense light could 'irreparably damage' the normal retina. He thus cautioned against indiscriminate funduscopy, advising students to first practise on kittens (the prospect of generations of blind cats obviously left him unmoved). Only then could they practise on patients 'who had long been hopelessly blind.' One infers a certain lack of confidence in his trainees.

It was soon realised that funduscopy would be useful to general physicians, who apparently had even more trouble than ophthalmologists in performing it. Many discarded the apparatus in frustration and condemned the technique. 'All too often,' bemoans Dr Solomon, 'after repeated trials the instrument is put aside as an instance of 'non possumus' - Latin for 'it doesn't work.' Considering the instructions of the time, one can regard this view with sympathy.

Soelberg Wells advocates first placing a lamp in close proximity to the patient's ear. With the right hand, a circular mirror is held and adjusted to reflect the light from the flame into the eye, 'so that it glows brilliant red,' while with the left hand, a biconvex lens is held two inches before the eye. The left ring finger should rest on the orbital margin, and the little finger be employed in raising the lid. 'Practice and perseverance' were necessary.

Even the lamp's construction was debated. Soelberg Wells magnanimously admitted that the best lamp was Moorfields (he was a King's man), which was a porcelain burner closed by fine gauze to steady the flame. The mirror's surround was the focus of oneupmanship - most opted for ivory or silver, but Hogg had his mounted in tortoiseshell and reported the fact in the journals.

Dixon believed a blue glass lamp would decompose red rays to make visualisation easier, and this may have narrowly missed becoming the ophthalmologists' equivalent of the barber's red stripe. More simply, Wilson used sunlight for funduscopy - when there was any - by the simple expedient of having the local carpenter cut a circular hole in his shutters. (These problems disappeared after 1884 with the advent of electrical ophthalmoscopes.)

Dr Williams of Cincinnati insisted that effective restraint of the patient was imperative. He advocated 'wearing one's ophthalmoscope' in the form of large round mirrors with central holes mounted in a spectacle frame. This would certainly leave the hands free, but the resultant appearance of the doctor would do little to calm the very young or mentally impaired subject.

Use of atropine was already accepted (remember there was no possibility of these patients driving themselves home!) but Solomon went one step further in advising the trainee to paralyse his own accommodation too!

Eventually the technique developed into a fine art, and teaching aids had their part to play. 'Perrin's artificial eye' was a brass contraption with a plano convex lens, a black pupil with a variable size perforation, and a posterior aperture into which papier mâché discs, painted to resemble abnormal fundi, could be inserted.

There must have been a moment of amazement for these nineteenth century ophthalmologists, as they, perhaps disbelieving early reports, saw the retina clearly for the first time. Sadly, this is largely submerged beneath the flood of argument. Spencer Wells alone records the sense of excitement, saying, 'the appearance of the vessels on the illuminated base is really beautiful.'

FIONA ROMAN

Dixon J. The ophthalmoscope. In: Braithwaite's retrospect of medicine. London: Simpkin and Co, 1853; XXXII: 284-68. Hogg J. The ophthalmoscope. In: Braithwaite's retrospect of medicine. London: Simpkin and Co, 1857; XXXV: 188-90. McMullen WH. The evolution of the ophthalmoscope BrF Ophthalmol 1917; 1: 593-600.

Soelberg Wells J. Use of the ophthalmoscope. In: Braithwaite's retrospect of mecidine. London: Simpkin and Co, 1871; LXIII 218-22.

Spencer Wells T. In: Braithwaite's retrospect of medicine. London: Simpkin and Co, 1854; XXIX: 368-71. 